\title{
pÿChange in First Graders Science-Related Competence Beliefs During Digitally Intensive Science Workshops
}

\section{Loukomies, Anni}

Springer

2019

pÿLoukomies , A , Juuti , K , Lavonen , J \& Salmela-Aro , K 2019 , Change in First Graders Science-Related Competence Beliefs During Digitally Intensive Science Workshops . in E McLoughlin , O E Finlayson, S Erduran \& P E Childs (eds), Bridging Research and Practice in Science Education : Selected Papers from the ESERA 2017 Conference . Contributions from Science Education Research, no. 6 , Springer, Cham , pp. 285-299 , ESERA 2017 , Dublin , Ireland , 21/08/2017 . https://doi.org/10.1007/978-3-030-17219-0_18

http://hdl.handle.net/10138/310837

https://doi.org/10.1007/978-3-030-17219-0_18

unspecified

acceptedVersion

Downloaded from Helda, University of Helsinki institutional repository.

This is an electronic reprint of the original article.

This reprint may differ from the original in pagination and typographic detail.

Please cite the original version. 


\title{
Change in First Graders' Science-Related Competence Beliefs during Digitally Intensive Science Workshops
}

\author{
Anni Loukomies ${ }^{1,3 *[0000-0002-7833-2895]}$, Kalle Juuti ${ }^{20000-0001-8696-2611]}$, Jari Lavonen ${ }^{2,3[0000-}$ \\ 0003-2781-7953] and Katariina Salmela-Aro ${ }^{20000-0003-1901-4712]}$ \\ ${ }^{1}$ Viikki Teacher Training School, Faculty of Educational Sciences, University of Helsinki, Fin- \\ land \\ ${ }^{2}$ Department of Education, Faculty of Educational Sciences, University of Helsinki, Finland \\ ${ }^{3}$ Centre for Education Practice Research (CEPR), University of Johannesburg, South Africa
}

*corresponding author, anni.loukomies@helsinki.fi

Abstract. The aim of this research was to examine if a set of three science and technology workshops would promote first-grade pupils' science-related competence beliefs. The first workshop dealt with electric circuits and related handicraft tasks. The second workshop involved programming with Lego Mindstorm robots. The third workshop was related to computer-based data logging. Fifty-nine Finnish first graders (age 7-8 years) participated in the digitally intensive science workshops and 38 pupils served as a control group. The data were analysed using a paired samples t-test. The analysis results reveal that the set of three workshops increased the pupils' science and technology related competence beliefs.

Keywords: Expectancy-Value Theory (EVT), Primary School Science and Technology

\section{Introduction}

The aim of this research was to examine if a set of three science and technology (S\&T) workshops would promote first-grade pupils' science-related competence beliefs. Research in the field of science education has shown that a decline occurs in students' science-related attitudes as they proceed in their school path. For example, according to her extensive review of relevant literature, Christidou (2011) argues that as they advance from primary to secondary education, students rapidly lose interest in science, and they do not see science-related careers as very attractive (Tytler 2014). Tytler (2014) also summarizes according to his review of the literature about science attitudes, that by the age of 14 , for the majority of students, the interest in pursuing further science studies has largely been formed. This fact highlights the importance of focusing on early science experiences. The Program for International Student Assessment (PISA) 
framework emphasises attitudes as a key component of an individual's science competence. Science competence includes, for example, interest, enjoyment and values related to science and school science. The percentage of students in Finland who reported that they 'agree' or 'strongly agree' with the statements measuring enjoyment of science learning ('I enjoy acquiring new knowledge in science') decreased on average from $64 \%$ to $56 \%$ between the PISA 2006 and 2016 measurements (Organisation for Economic Co-operation and Development [OECD] 2007, 2016). Further, the percentage of Finnish students who expect to work in a science-related occupation at age 30 is the lowest among the OECD countries, although the percentage increased slightly from $13 \%$ to $17 \%$ between the PISA 2006 and 2016 assessments. In general, students' low interest and engagement in science learning and science-related careers has received significant attention from policymakers and researchers (Osborne and Dillon 2008; Zeyer et al. 2013). The European Commission's Horizon 2020 Work Programme (European Commission, 2016) emphasises that school science should better represent real scientific practices and cater more effectively to the needs and interests of young people. Moreover, the Finnish national core curriculum emphasises the importance of student engagement in science learning (Finnish National Board of Education [FNBE] 2014).

In defining competence (or ability) beliefs, we follow the expectancy-value theory (EVT) of motivation proposed by Eccles and her colleagues (e.g. Eccles 2005). According to EVT, engagement and motivation towards a certain task depend, on one hand, on an individual's expectation of success and self-related beliefs (ability or competence beliefs) and, on the other hand, on values associated with the particular task (Eccles and Wigfield 2002; Pintrich 2003). Expectancies and values are assumed to directly influence performance, persistence and task choice (Eccles and Wigfield 2002).

Task characteristics that are assumed to influence choices can be positive or negative (Eccles and Wigfield 2002), and task-related values can be seen as positive valences of a task (Chow, Eccles and Salmela-Aro 2012). According to EVT, task-related values can be further distinguished as attainment value, intrinsic value and utility value. The first, attainment value, refers to experienced importance or significance of a topic. It refers to the perceived importance that individuals attach to performing well in, or being competent at, a task (Chow, Eccles and Salmela-Aro 2012: 1612). The second, intrinsic value, is defined as the expected enjoyment of engaging in a specific activity or task (Chow, Eccles and Salmela-Aro 2012). If the task holds intrinsic value, the activity itself will be the source of enjoyment, and the outcome of the task will not be perceived as extremely important. Intrinsic value has been found to be related to engagement and persistence in a task (Schunk, Pintrich and Meece 2007). The third, utility value, is the perceived usefulness of completing a task for obtaining some instrumental benefit, or facilitating the achievement of other immediate or long-term goals (Chow, Eccles and Salmela-Aro 2012). If the task holds utility value, the activity itself may not be perceived as interesting or enjoyable, but the outcomes of completing the task will be perceived as valuable.

Furthermore, according to EVT, there can be a negative valence related to the task in other words, the cost of engaging in the task (e.g. Eccles and Wigfield 2002; Gaspard et al. 2015) - because making one choice often eliminates other options (Eccles and 
Wigfield 2002). The negative aspects of engaging in a task can be categorised as effort cost, in terms of loss of time; emotional cost, such as stress and anxiety; and social cost, such as becoming an outsider to a peer group. For example, the effort cost relates to the fact that engaging in one task means having to neglect something else and having to make choices between activities. Emotional cost means having to accept a certain amount of anxiety, stress or fear of failure in order to achieve a goal (Schunk et al. 2007). Social cost may mean, for example, time spent away from friends in order to prepare for, and perform well on, a test. If the costs become too high with respect to the expected value of performing well, an individual may abandon the task; conversely, if the task is valued high, the costs will not matter. Despite the costs, if students' attainment and utility values can be influenced and the students can identify personal reasons why an activity relates to their lives, the intervention may promote greater engagement with the topic under study (Harackiewicz et al. 2015).

Besides task-related values, expectancy and personal competence beliefs are central in EVT. Competence beliefs are defined as students' evaluations of their competence in different areas (Eccles et al. 1983). These beliefs are conceived as broad beliefs about competence in a given domain, not one's expectancies of success on a specific upcoming task (Eccles and Wigfield, 2002: 119). In the present study, the emphasis was particularly on the students' science-related competence beliefs, although children and adolescents do not usually distinguish between these and expectancies, even though expectancies and competence beliefs are theoretically distinct concepts (e.g. Eccles and Wigfield 1995).

Within the field of science education research, there is a scarcity of studies on science-related competence beliefs among first-grade pupils. However, supporting the pupils' competence beliefs from primary school onwards might promote their sciencerelated motivation throughout their whole school path, because their beliefs about their achievement play a role in directing their behaviour and effort in learning situations (Eccles, 2009). However, the development of first graders' motivation has been examined in the context of other school subjects. When examining primary pupils' ability beliefs and performance in Finland, Viljaranta, Aunola and Hirvonen (2016) found evidence that in the context of mathematics and reading, the first-grade children show different motivational patterns or profiles that differ from each other (p. 370). Motivational pattern or profile refers to the idea proposed in person-oriented motivational research that associations between motivational variables are not necessarily similar for all individuals, but they constitute an individual profile. Viljaranta, Aunola and Hirvonen (2016: 371) even argue that when comparing beliefs in one's own abilities and intrinsic, the beliefs might play a bigger role in respect to performance in early school years. In other words, even though the intrinsic value associated with a task is low, the performance can be good if the pupil has high ability beliefs. According to a recent extensive review, Muenks, Wigfield and Eccles (2018) claim that this relationship between beliefs and performance strengthens across the school years, and even though smaller children seem to be very confident when it comes to their abilities, there is a tendency for competence beliefs to become more negative during the school years. Research related to competence beliefs does not provide a clear view of whether it is better 
to have realistic or overly optimistic competence beliefs from the point of view of motivation and performance (Muenks et al., 2018).

In addition, the competence-related beliefs of children become increasingly stable as they age, and this stability makes it difficult to change negative expectancy beliefs as children get older (Muenks et al., 2018). However, the ways in which learning situations are organised and structured with respect to instructional practices strongly influence children's expectancies and competence beliefs (Muenks et al., 2018, p. 9). When teachers hold high generalised expectations for student achievement and students perceive these expectations, the students achieve more and experience a greater sense of esteem and competence as learners (p. 9). Moreover, interventions have the power to reshape pupils' achievement-related beliefs (Muenks et al., 2018). In the present study, first graders were chosen as the target group for competence-beliefs-promoting S\&T workshops. The workshops were designed according to the principles of designbased research (Sandoval, 2014; Juuti, Lavonen and Meisalo, 2016 The design process is described in detail in the Workshops-section.

\section{Research question}

A set of three technology-intensive science workshops was organised to enhance the science and technology related competence beliefs of first-grade pupils. We assumed that the pupils' science-related competence beliefs may be fostered with offering possibilities to succeed in targeted activities. We also examined if the enhanced feeling of competence was transferable to another context. The research question was as follows: Does the set of three workshops promote science-related competence beliefs?

\section{Context of the study}

This research took place in Finland. The Finnish education system consists of a nineyear comprehensive curriculum, which is then followed by further studies in high school or vocational school. School starts in the year when pupils turn seven years old; the year prior to this, all children are permitted and recommended to attend pre-school. Pupils study in inclusive, heterogeneous groups, and most pupils go to a school near their home. In all groups participating in this research, there were pupils who spoke a language other than Finnish at home. Public schools (majority of the schools) are funded by municipalities, but there are also some private schools in Finland. However, for the pupils, comprehensive school is free of charge whether they go to a private or municipal school.

The national curriculum, which was revised in 2014, defines the minimum level of teaching for each subject for all pupils. The curriculum is subject-based. The subject science is officially called environmental studies and is taught in grades 1 to 6 . It integrates biology, geography, physics, chemistry and health education. In the present study, the workshops were most often related to the physics content. In the curriculum, transversal competencies are also highly emphasised. In the core curriculum, these 
competencies refer to an entity that encompasses knowledge, skills, attitude, values and will. Competence also means the ability to apply knowledge and skills in a given situation. The manner in which the pupils will use their knowledge and skills is influenced by the values and attitudes they have adopted and their willingness to act. Competence development is influenced not only by the contents on which the pupils work but also by how they work and how their interaction with the environment functions (Finnish National Board of Education 2014).

The transversal competencies introduced in the Finnish national core curriculum are thinking and learning to learn, cultural competence, interaction and self-expression, taking care of oneself and managing daily life, multiliteracy, information and communications technology (ICT) competence, working life competence and entrepreneurship and participation, involvement and building a sustainable future. ICT competence is emphasized in the workshops. In the core curriculum, it is recommended the pupils are supported in familiarizing themselves with various ICT applications, and that they are guided in using ICT in exploratory and creative work. In this research, pupils use programming and data logging applications in order to reach the aims expressed in the core curriculum. The Finnish national core curriculum introduces multidisciplinary learning modules that integrate the perspectives of different school subjects and enrich the combination with transversal competencies. Multidisciplinary learning modules promote the achievement of goals set for basic education. To ensure that all learners can engage in exploratory work that is of interest to them, each learner must be provided with an opportunity to join a multidisciplinary learning module at least once during each school year. Schools must also provide opportunities for experimentation, exploration, active learning, physical activity and play. Cultural diversity and language awareness are also key principles that guide the development of the school culture (Finnish National Board of Education 2014). The workshops introduced in this article shared features of multidisciplinary learning modules, as they incorporated enquiry skills, programming and science content.

\section{$4 \quad$ Participants and procedure}

A total of 97 first grade pupils (pupils' age 7 - 8 years) participated this study. Three first-grade) classes in one school $(1 . \mathrm{N}=20,2 . \mathrm{N}=20,3 . \mathrm{N}=19,59$ altogether) participated in the workshops. The school is located in a suburban area, with relatively high SES. There were 38 pupils in the control group from two other school in the Helsinki Eastern suburban area.

Substantial research has shown that students' expectancies predict future performance, even when controlling for previous performance (Muenks et al., 2018, p. 7). When teachers hold high generalised expectations for students' achievement and students perceive these expectations, the students achieve more, experience a greater sense of esteem and competence as learners, and resist engaging in problem behaviours (Muenks et al., 2018, p. 9). The high expectations of teachers are communicated in the 
selection of challenging tasks for pupils to perform and through the teachers' belief in the pupils' competence to perform well in these tasks. The teachers communicate this belief in the pupils' capabilities by offering encouragement in spoken form throughout the lesson and especially in situations where the pupils are struggling with some aspect of the task. The workshops were designed according to the Finnish national core curriculum (Finnish National Board of Education 2014), especially the parts such as science content, enquiry skills and transversal competencies. The enquiry skills that first graders should adopt, according to the Finnish national core curriculum, are as follows: Science teaching in the first grade should encourage the pupils to ask questions and use classroom discussions as a starting point for small enquiry tasks. The pupils should be guided to make observations by using their senses and simple equipment, and further present the results of their enquiry projects. The pupils should also be guided to act responsibly and to follow instructions. Finally, the pupils should be guided to familiarise themselves with technology, and be encouraged to try, invent, build and create in collaboration with others, and use ICT as a means of communicating their activities to others. These aims introduced in the Finnish national core curriculum for first-grade science were taken into account, when planning the workshops.

The designing of the teaching sequences followed design principles introduced by Sandoval (2014). He introduces a conjecture-mapping technique in order to 'specify theoretically salient features of a learning environment design and mapping out how they are predicted to work together to produce desired outcomes' (p. 2). In the present study, the elements of the conjecture map were as follows. The high-level conjecture was to engage pupils to perform challenging tasks and, through that procedure, foster their task-related competence beliefs. This conjecture was ensured through scaffolding all the pupils to perform challenging tasks in the workshops. Verbal and concretical scaffolding were an essential part of the design. The mediated outcome was a result of ensuring that all pupils could carry out the workshop tasks by offering support from teachers. Further, as a learning outcome, pupils' competence beliefs were measured in the competence belief questionnaire administered about a month after the workshops.

Design conjectures take the general form, 'if learners engage in this activity with these tools, through this discursive practice, then this mediating process will emerge' (Sandoval, 2014: 7). In the present study, design conjecture was articulated in a form that if pupils engage in digitally intensive science workshops that involve producing electric circuits, programming robots and taking measurements, and if they are scaffolded, the pupils manage to complete the tasks and get support for their competence beliefs.

The embodiment of the design conjectures encompassed tools and materials, task structures, participant structures and discursive practices The workshops were designed so that the tools and materials were evidently challenging for pupils. Pupils used electrical components, Lego EV3 robots, computers and Logger Pro computer-based data logging equipment, for example. At the time of the workshops, typically, fifth graders conducted electric circuit investigations or programming practices with Lego EV3 robots. Computer-based data-logging was applied occasionally at the middle school level. Many digitally intensive tools that are not used in everyday lessons were used in the 
workshops. The tools and materials used in the workshops are described in more detail in the section introducing the workshop content and practice.

The general task structure was intended to answer the question, 'What are the pupils expected to do?' In the present study, pupils attending the workshops were expected to perform certain tasks, one at a time. The structure of each task was designed such that pupils would have limited possibilities to compare their performance with that of others. Further, the task was designed so that it would take all pupils about the same amount of time to complete it. In the latter part of the task, there was a possibility of varying the task in order to differentiate the teaching according to the pupils' different needs. There were also several adults in the classroom to support the pupils.

In the first workshop, the pupils worked alone; in the second workshop, they worked in pairs; and in the third one, the pupils worked in a group. The tasks were designed to support the grouping of pupils in that particular situation. In the first workshop, each pupil generated their own piece of art, which they were able to take home with them; therefore, working alone was the most suitable way of working. In the second workshop, the pupils worked in pairs, because the task required negotiation and there were suitable tasks for two people. In the last workshop, four pairs of hands were needed to handle the equipment; therefore, group work was chosen as the instructional method.

The workshops exposed the pupils to discursive practices or 'ways of talking' that aimed at emphasising positive aspects of their performance. During the whole class discussions before introducing the task and after the completion of the tasks, pupils' persistence and performance of the task were praised. Furthermore, the challenge of the task was emphasised. All adults attending the situation (teacher-researcher, teacher, researcher and assistant) gave pupils verbal reassurance that they would manage to complete the challenging tasks. In the scaffolding situations, reasons for the difficulties were attributed to the complex digital tools, not to the pupils' performance. Further, in scaffolding situations, pupils were told that other pupils had faced similar difficulties and had managed well in overcoming them. Further, it was mentioned that this kind problem solving (e.g. 'Solving contiguity disturbance problems in connectors is part of working with digital tools, and now you have experienced how to solve these kind of problems') is typical in S\&T-related tasks. Thus, in the workshops, pupils achieved success when performing well in a very challenging task.

Theoretical conjectures in a conjecture map take the following general form: 'if this mediating process occurs it will lead to this outcome' (Sandoval, 2014: 7). In our case, the theoretical conjecture could be stated as follows: If pupils manage to perform a challenging and digitally intensive task, their competence beliefs regarding the task will increase. The challenges of the task and the teachers' beliefs in the students' competence were communicated to the pupils. The data collection methods described in the methods section were intended to examine the realisation of the theoretical conjecture.

In what follows, the workshop activities are described in detail. The activities took place during the spring semester of 2016 and included three 90-minute S\&T workshops. The activities in the workshops were planned carefully to follow the Finnish national core curriculum for basic education for primary science (Finnish National Board of Education 2014); therefore, nothing outside the curriculum was included in the workshops. In other words, both experimental and control groups were taught according to 
the curriculum. In Finland, teachers enjoy broad autonomy with respect to implementing the curriculum and choosing activities and learning materials, and enquiry skills and hands-on experiments are strongly recommended as part of the science subject.

First workshop: The topic of the first workshop was electric circuits. First, pupils individually familiarised themselves with the components of an electric circuit, put the batteries into the battery case and tried to light the bulb. The components were named in a teacher-led discussion. After succeeding in this task, the next task about crafts was introduced. The instruction was to connect the components (batteries and LEDs) with a conductive aluminium tape in such a way that all LEDs would light up at the same time. The pupils were shown a model of the piece of work, which looked like a star shape. Pupils were given as much assistance as they needed. If the LEDs did not light up, pupils were assisted in determining the reason for this. The idea of connecting all the components carefully to build a circuit was emphasised. This task took up the remainder of the lesson.

In the first workshop, batteries, battery cases and bulbs, LEDs, conductive aluminium tape and cardboard were used as tools and materials in order to prepare the artefacts.

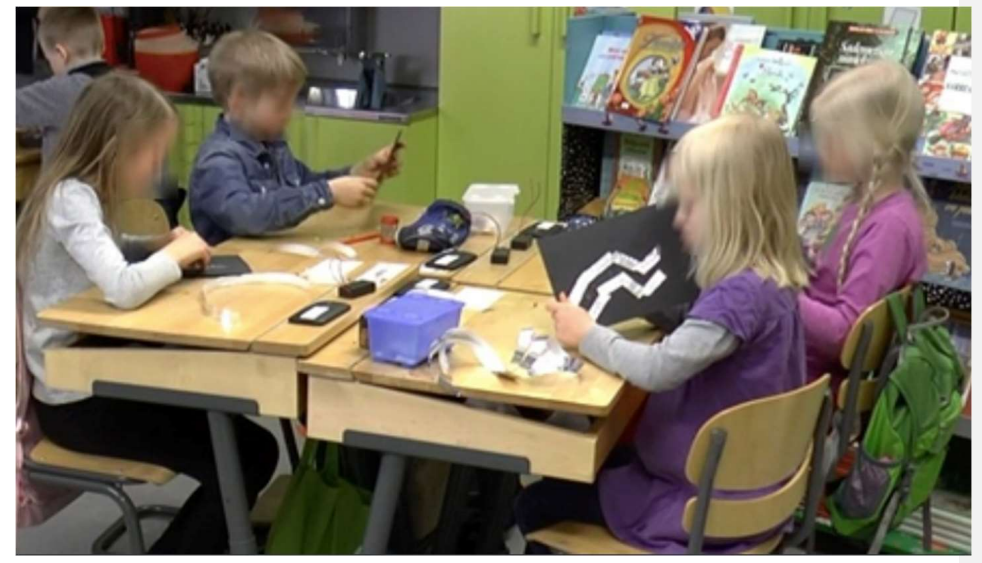

Fig. 1. Pupils' activities during the first workshop.

Second workshop: The topic of the second workshop was programming. The pupils first familiarised themselves with Lego programming with Mindstorm EV3 robots and the related software. Since most Finnish children play with Lego even before they go to school, the theme of the lesson was familiar to them. However, programming with 
Lego EV3 did not involve much Lego building, as the robot vehicles had been assembled in advance. This is because when starting to learn to use the programming software, the components of the robot need to be in their exact places, and there is little room for creativity. Afterwards, when the basics of programming are learnt, different creations can be constructed.

The lesson began by showing the pupils three videos in which there were astonishing and complex constructions built using Lego robots. Then the pupils were given the basic instructions for using the program, how the robot could be switched on and how to download the program. They tried out these tasks together. Then the pupils received a task sheet with the instructions, which they were told to follow carefully. For the rest of the lesson, the pupils practised programming in pairs, downloaded their programs into the robot and followed how the robot executed the program.

In the second workshop, laptops, Lego EV3 Mindstorm software, EV3 robots (basic model), worksheets for testing the programs and programming challenges were used as tools and materials.

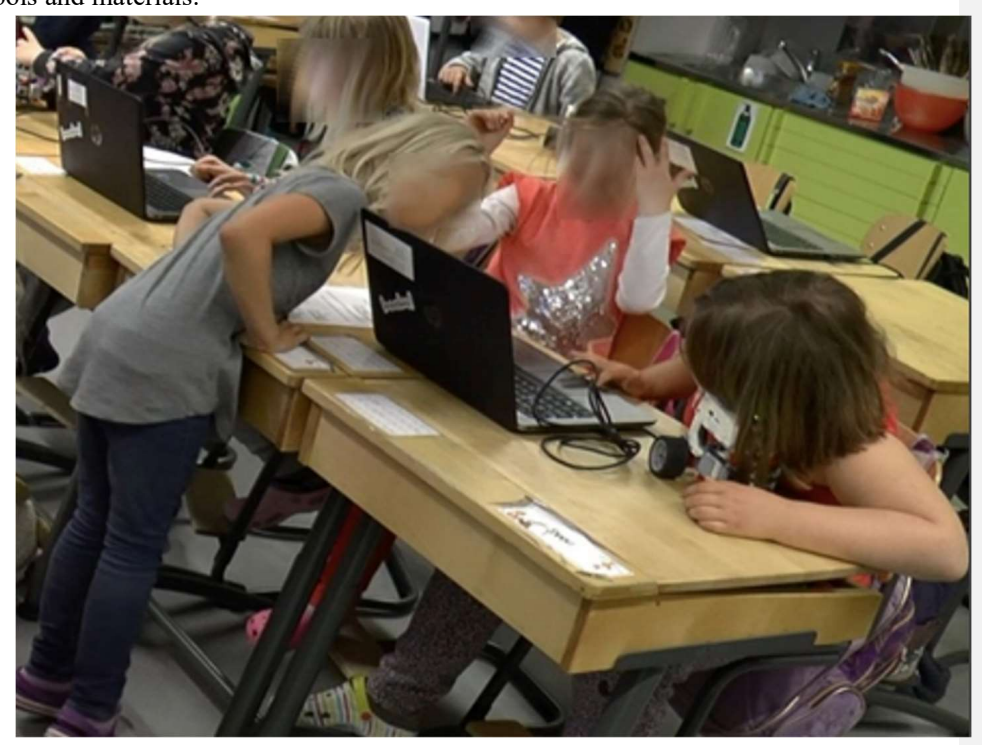

Fig. 2. Pupils' activities during the second workshop.

Third workshop: The topic of the third workshop was related to computer-based data logging. In small groups ( 3 to 4 pupils per group), the pupils used Vernier LabQuest2 data logging equipment to measure temperature changes, and they drew graphs on paper depicting their data. Certain phenomena were introduced to the pupils (e.g. water 
boiling, ice melting), and they were asked to record temperature changes within certain time intervals related to those phenomena. Then they constructed a graph based on the data and interpreted each other's graphs.

In the third workshop, Vernier LabQuest portable data logger, temperature probes, beakers and electric kettles were used as tools and materials. Additionally, worksheets for measurements were prepared.

Activities in the control group: The control group studied according to the Finnish National Core Curriculum (2014). In Finland the teacher has a high level of autonomy in preparing the yearly plan and planning the teaching sequences. The control group followed the teacher's plans and did not take part in the workshop activities as described above

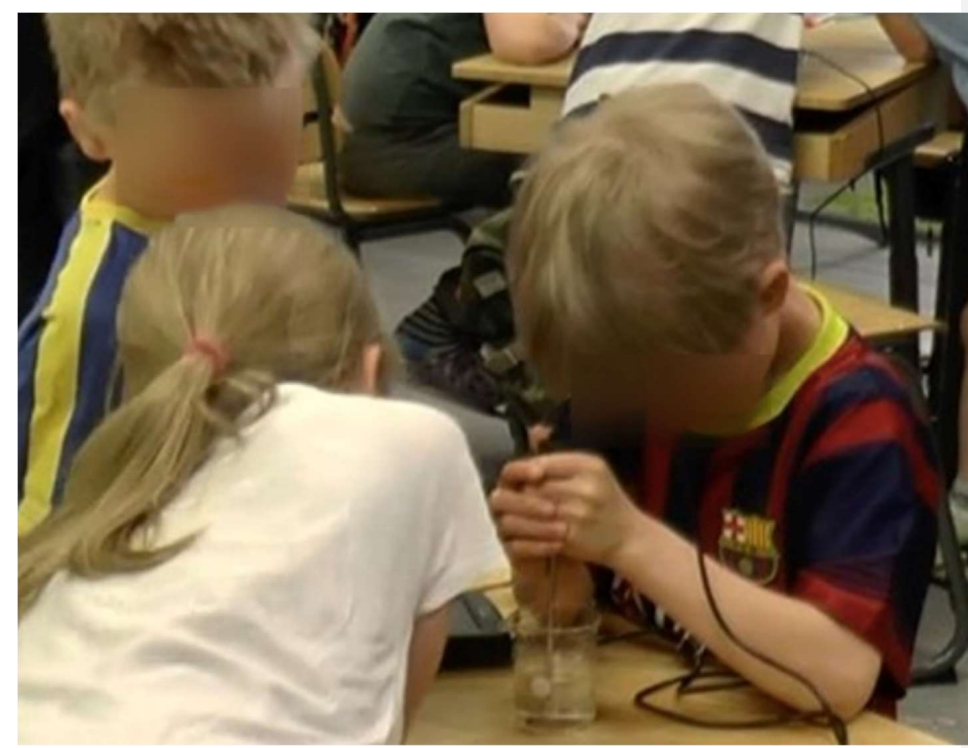

Fig. 3. Pupils' activities during the third workshop.

The experimental group answered a questionnaire about their competence beliefs before and after the workshops, in February and in May. The control group participated in ordinary teaching according to curriculum, and answered the questionnaire twice, in February and May as the experimental group. Taking into consideration the pupils' age, the items were highly contextual, focusing on concrete science, technology and craft activities. In the questionnaire, four items focused on the workshop topics and two 
items focused on other topics, and they served as control topics. The post-test took place a month after the workshops. In the questionnaire, the children were asked to evaluate how competent they felt themselves with respect to the topics included in the workshops and topics not included in the workshops $(1=$ Not good at the activity at all, $5=$ Very good at the activity). The items on this topic were as follows:

\section{Science-related skills practiced in the workshops}

How well do you think you can:

- Change batteries of a toy?

- Change a light bulb?

- Program a robot?

- Measure water temperature with a thermometer?

\section{Science-related skills outside the workshops}

How well do you think you can:

- Use a sewing machine?

- Measure the amount of flour when baking?

There were one or two researchers per class instructing and guiding the data collection. Since not all first graders are very fluent readers by February, the answering proceeded as a guided activity, one item at a time, where the researcher read the item aloud and explained the unfamiliar concepts and showed pictures of the devices, if necessary. The principles of the Likert-scale were explained as many times as needed, and the construct of the scale was explained. The data were analysed through a paired samples t-test.

\section{$5 \quad$ Results}

The research question was Does the set of three workshops promote science-related competence beliefs? The question was answered by employing a pre-post questionnaire design. In Table 1, the means and standard deviations are presented. According to the paired samples t-test, the workshops increased science-related competence beliefs related to the content of the workshops in the experimental group. However, there was no statistically significant change in the control group (see Table 2). Fig. 4 shows the mean values of the experimental and control groups between the pre- and post-workshop questionnaires.

Table 1. Paired samples descriptive statistics.

\begin{tabular}{|c|c|c|c|}
\hline & & & Control Group \\
\hline & Pre & Post & Pre \\
\hline
\end{tabular}




\begin{tabular}{|l|c|c|c|c|c|c|c|c|c|c|c|}
\hline & $\mathrm{N}$ & $\begin{array}{l}\text { Mea } \\
\mathrm{n}\end{array}$ & $\mathrm{SD}$ & Mean & $\mathrm{SD}$ & $\mathrm{N}$ & $\begin{array}{l}\text { Mea } \\
\mathrm{n}\end{array}$ & $\mathrm{SD}$ & $\begin{array}{l}\text { Mea } \\
\mathrm{n}\end{array}$ & $\mathrm{SD}$ \\
\hline $\begin{array}{l}\text { Science-related topics in the workshops } \\
\text { How well do you think you can }\end{array}$ & $\begin{array}{l}\text { Change bat- } \\
\text { teries of a } \\
\text { toy? }\end{array}$ & 45 & 2.58 & 1.57 & 3.33 & 1.64 & 35 & 2.89 & 1.73 & 3.03 & 1.58 \\
\hline $\begin{array}{l}\text { Change a } \\
\text { light bulb? }\end{array}$ & 42 & 1.60 & 1.29 & 2.12 & 1.55 & 34 & 1.59 & 1.37 & 1.74 & 1.48 \\
\hline $\begin{array}{l}\text { Program a } \\
\text { robot? }\end{array}$ & 39 & 1.64 & 1.39 & 4.26 & 0.97 & 30 & 1.83 & 1.42 & 2.43 & 1.61 \\
\hline $\begin{array}{l}\text { Use a ther- } \\
\text { mometer? }\end{array}$ & 43 & 2.26 & 1.56 & 4.09 & 1.31 & 32 & 2.44 & 1.68 & 2.69 & 1.69 \\
\hline $\begin{array}{l}\text { Topics outside the workshops } \\
\text { How well do you think you can }\end{array}$ & 41 & 2.05 & 1.56 & 2.41 & 1.73 & 34 & 2.00 & 1.58 & 1.71 & 1.32 \\
\hline $\begin{array}{l}\text { Use a sew- } \\
\text { ing ma- } \\
\text { chine? }\end{array}$ & & & & & & & & & & & \\
\hline $\begin{array}{l}\text { Measure } \\
\text { flour? }\end{array}$
\end{tabular}

Table 2. Paired samples t-test statistics $(p=0.05)$.

\begin{tabular}{|c|c|c|c|c|c|c|}
\hline & \multicolumn{3}{|c|}{ Workshop } & \multicolumn{3}{|c|}{ Control } \\
\hline & $\mathrm{t}$ & $\mathrm{df}$ & $p$ & $\mathrm{t}$ & $\mathrm{df}$ & $p$ \\
\hline \multicolumn{7}{|c|}{ Science-related topics in the workshops } \\
\hline $\begin{array}{l}\text { Change batteries of a } \\
\text { toy? }\end{array}$ & -3.07 & 44 & $.004^{* *}$ & -.70 & 34 & .492 \\
\hline Change a light bulb? & -2.05 & 41 & $.047^{*}$ & -.53 & 33 & .599 \\
\hline Program a robot? & -10.32 & 38 & $.000 * * *$ & -1.78 & 29 & .086 \\
\hline Use a thermometer? & -6.38 & 42 & $.000 * * *$ & -.83 & 31 & .413 \\
\hline \multicolumn{7}{|c|}{$\begin{array}{l}\text { Topics outside the workshops } \\
\text { How well do you think you can }\end{array}$} \\
\hline Use a sewing machine? & -1.36 & 40 & .183 & 1.12 & 33 & .270 \\
\hline $\begin{array}{l}\text { Measure the amount of } \\
\text { flour? }\end{array}$ & .46 & 43 & .649 & -1.38 & 30 & .176 \\
\hline
\end{tabular}




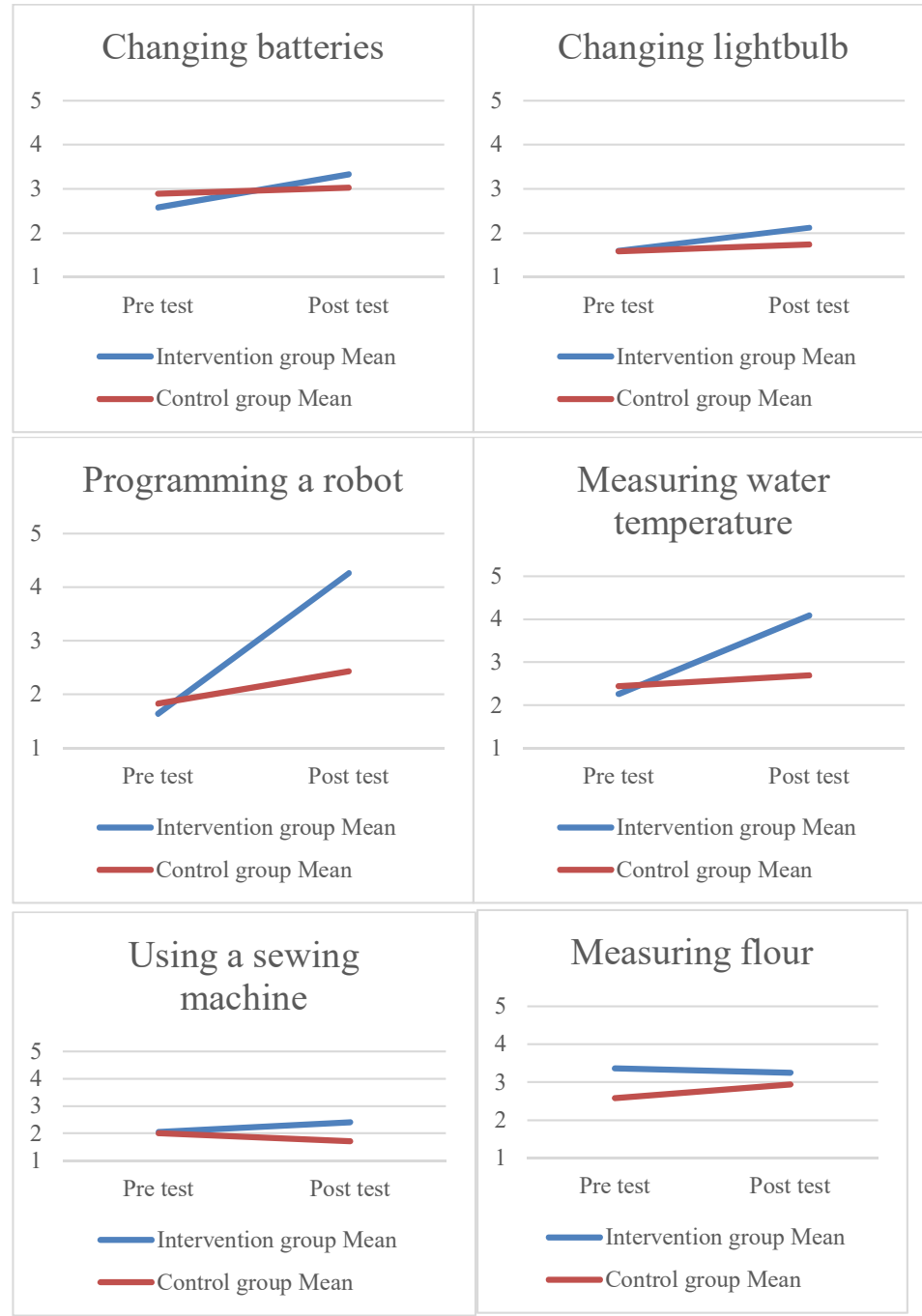

Fig. 4. Change in experimental group and control group mean values between pre-test and post-test. 


\section{Discussion}

In the present study, we examined first-grade pupils' science and technology related competence beliefs in digitally intensive workshops. In the workshops, pupils engaged in S\&T activities that encompassed electricity crafting tasks, programming with Lego EV3 devices and computer-based data logging. The workshops, which were planned to follow the national core curriculum for basic education for primary science (Finnish National Board of Education 2014), included activities that were challenging enough, but planned in such a way that the pupils could manage to accomplish them. This is in line with Eccles' (2009) argument that success in moderately difficult but achievable tasks (activities that provide both a challenge and the opportunity to achieve mastery) is likely to lead to the greatest increases in expectancy-related self-concepts (p. 85).

Based on the results, we argue that with the set of workshops described in this paper, it is possible to promote first-grade pupils' science and technology related competence beliefs. There was a statistically significant difference in the items concerned in the workshops. The results are in line with Yeager and Walton's (2011) argument that a correctly timed and planned motivational intervention may be effective in supporting pupils' self-beliefs. According to the extensive review of Muenks et al. (2018), the competence-related beliefs of children become increasingly stable as they age, and there is a tendency for competence beliefs to become more negative during the school years. Furthermore, Viljaranta, Aunola and Hirvonen (2016) claim that changes occur in the motivational patterns or profiles of children's motivation at the beginning of their schooling, even though some stability can be found in their motivational patterns already in the first grade. The increasing stability of pupils' competence beliefs makes it difficult to change negative expectancy beliefs as they get older (Muenks et al., 2018), and on the other hand, beliefs about achievement direct the pupils' behaviour and effort in learning situations (Eccles 2009). Therefore, it is crucial to try to foster positive competence beliefs in younger pupils through ensuring that the pupils realize they are doing something challenging, that they manage to complete the task, that they are praised about their perseverance and about the completed successful outcome. If there is a tendency for the competence beliefs of pupils to decline, it may be useful to ensure that these beliefs are as high and positive as possible in the early years of schooling, before they start becoming more stable. There was no statistically significant difference in the competence beliefs of the control group between measurements 1 and 2. There was either no statistically significant difference in the competence beliefs of the experimental group in the items that weren't included in the workshops. It can be interpreted that the influence of the workshops cannot be transferred into the context of other topics with first grade pupils.

As the research data were collected when the pupils were in the first grade, this raises some validity issues, mainly related to the pupils' reading and thinking skills - that is, how well they understood the questions and how well they were able to concentrate when answering them. To diminish the probable biases, the items were read aloud to 
the pupils, and the researcher made sure that everyone could follow the procedure. With respect to these results, science and technology are understood in a narrow sense as a particular science-related task (e.g. programming a robot). The statistically significant change cannot be tracked outside the workshop topics based on these results. This may be related to young children's way of perceiving the world and their reduced ability to see the big picture and connections between parts. Although the workshops included many kinds of activities and were digitally intensive, it is possible to implement such an approach in ordinary teaching.

\section{Acknowledgements}

This material is based upon work supported by the Finnish Academy (No. 294228 and 298323). The opinions expressed here are those of the authors and do not represent the views of the funding agency. The authors acknowledge the Finnish Academy.

\section{References}

Chow, A., Eccles, J., \& Salmela-Aro, K. (2012). Task value profiles across subjects and aspirations to physical and IT-related science in the United States and Finland. Developmental Psychology, 48(6), 1612-1628. doi: 10.1037/a0030194

Christidou, V. (2011). Interest, attitudes and images related to science: Combining students' voices with the voices of school science, teachers, and popular science. International Journal of Environmental and Science Education, 6, 141-159.

Eccles, J. (2005). Subjective task-value and the Eccles et al. model of achievement-related choices. In A. J. Elliot \& C. S. Dweck (Eds.), Handbook of competence and motivation. New York, NY: Guilford Press.

Eccles, J. (2009). Who am I and what am I going to do with my life? Personal and collective identities as motivators of action. Educational Psychologist, 44(2), 78-89. doi: $10.1080 / 00461520902832368$

Eccles, J., \& Wigfield, A. (1995). In the mind of the achiever: The structure of adolescents' academic achievement-related beliefs and self-perceptions. Personality and Social Psychology Bulletin, 21, 215-225.

Eccles, J. S., \& Wigfield, A. (2002). Motivational beliefs, values and goals. Annual Review of Psychology, 53, 109-132. doi: 10.1146/annurev.psych.53.100901.135153

Eccles, J., Adler, T. F., Futterman, R., Goff, S. B., \& Kaczala, C. M. (1983). Expectancies, values and academic behaviors. In J. T. Spence (Ed.), Achievement and achievement motivation. San Francisco, CA: W. H. Freeman.

European Commission. (2016). http://ec.europa.eu/research/participants/data/ref/h2020/wp/2016 2017/main/h2020-wp1617-intro_en.pdf. Visited 3.5.2018.

Finnish National Board of Education. (2014). National core curriculum for basic education. Finnish National Board of Education, Publications 2016:5. 
Gaspard, H., Dicke, A-L., Flunger, B., Schreier, B., Häfner, I., Trautwein, U., \& Nagengast, B. (2015). More value through greater differentiation: Gender differences in value beliefs about math. Journal of Educational Psychology, 107(3), 663-677. doi: 10.1037/edu0000003

Harackiewicz, J. M., Canning, E. A., Tibbets, Y., Priniski, S. J., \& Hyde, J. S. (2015). Closing achievement gaps with a utility-value intervention: Disentangling race and social class. Journal of Personality and Social Psychology, 111(5), 745-765. .doi:10.1037/pspp0000075

Juuti, K., Lavonen, J., \& Meisalo. V. (2016). Pragmatic Design-Based Research - Designing as a Shared Activity of Teachers and Researches. In D. Psillos, \& P. Kariotoglou, (Eds.)Iterative Design of Teaching-Learning Sequences: Introducing the Science of Materials in European Schools. . Dordrecht: Springer 35-46.doi: 10.1077/978-94-007-7808-5

Muenks, K., Wigfield, A., \& Eccles, J. (2018). I can do this! The development and calibration of children's expectations for success and competence beliefs. Developmental Review 48, 24-39. doi: 10.1016/j.dr.2018.04.001

Organisation for Economic Co-operation and Development. (2007). PISA 2006: Science competencies for tomorrow's world, Volume 1: Analysis. Paris, France: OECD. doi:10.1787/9789264040014-en

Organisation for Economic Co-operation and Development. (2016). PISA 2015 results (volume I): Excellence and equity in education. Paris, France: OECD. doi:10.1787/9789264266490en

Osborne, J., \& Dillon, J. (2008). Science education in Europe: Critical reflections. London, UK: The Nuffield Foundation.

Pintrich, P. R. (2003). A motivational science perspective on the role of student motivation in learning and teaching contexts. Journal of Educational Psychology, 95(4), 667-686. doi: 10.1037/0022-0663.95.4.667

Sandoval, W. (2014). Conjecture mapping: An approach to systematic educational design research. Journal of the learning sciences, 23(1), 18-36. doi: 10.1080/10508406.2013.778204

Schunk, D. H., Pintrich, P. R., \& Meece, J. L. (2007). Motivation in education. Upper Saddle River, NJ: New Jersey: Pearson Education.

Tytler, R. (2014). Attitudes, identity, and aspirations toward science. In N. G. Lederman \& S. K. Abell (Eds.), Handbook of research on science education (pp. 82-103). New York, NY: Routledge.

Viljaranta, J., Aunola, K., \& Hirvonen, R. (2016). Motivation and academic performance among first-graders: A person-oriented approach. Learning and Individual Differences, 49, 366-372. doi: 10.1016/j.lindif.2016.06.002

Yeager, S. D., \& Walton, G. M. (2011). Social-psychological interventions in education: They're not magic. Review of Educational Research, 81, 267-301. doi: 10.3102/0034654311405999

Zeyer, A., Çetin-Dindar, A., Md Zain, A. N., Juriševič, M., Devetak, I., \& Odermatt, F. (2013). Systemizing: A cross-cultural constant for motivation to learn science. Journal of Research in Science Teaching, 50(9), 1047-1067. doi: 10.1002/tea.21101 